\title{
A Legitimidade da Recusa da Transfusão de Sangue por Motivos Religiosos à Luz do Direito à Saúde nos 30 Anos da Constituição
}

\author{
José Renato Venâncio Resende
}

Mestrado em Direito pela Universidade Federal de Uberlândia, na área de Direitos Fundamentais. Foi bolsista/pesquisador do Programa Jovens Talentos para a Ciência (2013-2014), coordenador discente do projeto Verdade, Memória e Justiça, do Escritório de Assessoria Jurídica Popular (Esajup) da Universidade Federal de Uberlândia (2015) e diretor-presidente da Companhia Artimanha Direito e Arte (2014-2016). Também foi bolsista e pesquisador do Centro Brasileiro de Estudos em Direito e Religião (Cedire), coordenador do Laboratório de Direitos Humanos e Justiça Global (LabDH) e bolsista Capes (2018-2019). http://lattes.cnpq.br/1591205186119384. https://orcid.org/0000-0003-1170-7047. jrenatoresende@gmail.com

\section{Rodrigo Vitorino Souza Alves}

Professor da Faculdade de Direito da Universidade Federal de Uberlândia. Pesquisador do Ratio Legis - Centro de Investigação e Desenvolvimento em Ciências Jurídicas da Universidade Autónoma de Lisboa. Foi Academic Visitor na Universidade de Oxford. Mestrado em Direito pela Universidade Federal de Uberlândia. Doutor em Direito pela Universidade de Coimbra, Portugal. http://lattes.cnpq.br/7254385824510699. https://orcid.org/0000-0001-5973-9588.rodrigo.vitorino@ufu.br

RESUMO

A vida, a saúde e a liberdade religiosa são direitos fundamentais consagrados pela Constituição de 1988 e que devem ser igualmente protegidos. Há, entretanto, situações em que eles podem entrar em (aparente) conflito, como quando, por exemplo, um cidadão nega-se a receber transfusão sanguínea alegando motivos religiosos. Nestes casos, surgem alguns questionamentos bioéticos, médicos e jurídicos para os quais o Direito ainda não tem resposta definitiva, em especial no que se refere a como o profissional da saúde deve proceder. A partir desse problema, o presente artigo busca entender, com a análise do direito à saúde, em quais casos a recusa à hemotransfusão pode ser legítima e como ela deve ser tratada.

Palavras-chave: Direito à saúde. Liberdade religiosa. Transfusão de sangue.

\section{THE LEGITIMACY OF REFUSING BLOOD TRANSFUSION FOR RELIGIOUS REASONS UNDER THE RIGHT TO HEALTH IN THE 30 YEARS OF CONSTITUTION}

\section{ABSTRACT}

Life, health and religious freedom are fundamental rights enshrined in the 1988 Constitution and must also be protected. However, there are situations where they may come into (apparent) conflict, such as when, for example, a citizen refuses to receive blood transfusion on religious grounds. In these cases, some bioethical, medical and legal questions arise for which the Law has not yet definitive answer, especially as to how the health professional should proceed. From this problem, the present article seeks to understand, from the analysis of the right to health, in which cases the refusal to blood transfusion may be legitimate and how it should be treated.

Keywords: Right to health. Religious freedom. Blood transfusion.

SUMÁRIO

1 Introdução. 20 direito fundamental à saúde na Constituição de 1988. 3 As "posições jurídicas" do direito à saúde. 4 As Testemunhas de Jeová: religião, saúde e direitos. 4.1 Breve histórico. 4.2 A questão jurídica da recusa da transfusão de sangue. $4.3 \mathrm{O}$ dever prestacional sanitário relativo às Testemunhas de Jeová. 5 Considerações finais. 6. Referências. 


\section{Humanos e \\ Democracia}

\section{INTRODUÇÃO}

O direito à saúde pública é uma das conquistas trazidas pela Constituição de 1988, que o elenca entre os direitos sociais, junto ao rol estabelecido no artigo 6ㅇ. Mais adiante, ressaltando o compromisso do Estado com seu adimplemento, exara nas letras do artigo 196: "a saúde é direito de todos e dever do Estado, garantido mediante políticas sociais e econômicas que visem à redução do risco de doença e de outros agravos e ao acesso universal e igualitário às ações e serviços para sua promoção, proteção e recuperação" (BRASIL, 1988).

Pela leitura da definição trazida no texto constitucional, salta aos olhos o compromisso do Estado na prestação da saúde pública mediante um acesso universal e igualitário. Eis que exatamente aqui se inicia a celeuma que este artigo se propõe a estudar.

Dizer de acesso igualitário lança no plano fático uma característica que não condiz com a realidade: pessoas não são iguais, e demandas sanitárias, de forma contingente, também não o são. De maneira específica, a diversidade avoluma-se e se torna particularmente preocupante em relação às Testemunhas de Jeová, que, segundo sua crença, é-lhes proibido receber, terapeuticamente ou de qualquer outra forma, transfusão sanguínea.

Diante desta diferença, e da opção pelo critério da igualdade, surge o problema de pesquisa: É legítima a recusa de pacientes Testemunhas de Jeová de receberem transfusão de sangue, prescrita pela equipe médica responsável, numa situação em que sua saúde encontra-se em risco? A hipótese de trabalho é a de que o direito à saúde, assim como todos os outros direitos fundamentais, tem um viés negativo, que protege o indivíduo da interferência indesejada do Estado.

A hipótese de trabalho é a de que a adoção da ideia de igualdade em direito sanitário impede o pleno atendimento das doenças refratárias, o que é estimulado pela invisibilidade quanto a elas, aliada à falta de poder de representatividade política desta classe.

O objetivo geral, por sua vez, é enfrentar um impasse jurídico recorrente não apenas nos tribunais, mas também no cotidiano de diversos hospitais e clínicas que lidam com tal situação, e que, muitas vezes, por dificuldades em resolvê-la e chegar a um consenso com o paciente ou com seus familiares, transferem o desacordo ao Judiciário. Entende-se, pois, que o Direito não pode se furtar de analisar minuciosamente essa questão. Como objetivos específicos, têm-se a análise do direito fundamental à saúde e de sua dimensão negativa e o breve estudo sobre as Testemunhas de Jeová e suas crenças e restrições em relação à transfusão de sangue.

Pode-se questionar se não seria mais adequado analisar a suposta legitimidade da recusa de transfusão de sangue por parte das Testemunhas de Jeová sob o viés único da liberdade religiosa ou da liberdade de crença, assim como é corriqueiramente feito, em vez de valer-se da perspectiva do direito sanitário, como se pretende. Sem, entretanto, desprezar os trabalhos já, até aqui, realizados, considera-se igualmente importante que se leve em consideração um estudo pela ótica sanitária, pois entende-se que, enquanto as Testemunhas de Jeová, numa situação de alegada necessidade de transfusão sanguínea, opõem o escudo das liberdades de religião e de crença, o Estado e a equipe médica enxergam, sobretudo, a saúde em risco e uma morte iminente. 
Ademais, ainda que muito se tenha escrito sobre todos esses temas (vida saúde, liberdade religiosa, transfusão de sangue em Testemunhas de Jeová, etc.), entende-se que eles continuam atuais e de grande relevo, haja vista, por exemplo, que o caso da acusação de homicídio aos pais da adolescente Juliana Bomfim da Silva - que recusaram que a filha recebesse transfusão por razões religiosas - só foi definitivamente julgado em 2014 (BRASIL, 2014), além de diversos outros casos similares relatados rotineiramente, como já mencionado. Fica, assim, portanto, justificada a escolha feita.

Enquanto método de abordagem, utilizou-se o argumentativo, por se entender o mais adequado para a pesquisa com direitos fundamentais. Já o método de procedimento aplicado foi o estudo de caso, haja vista os diversos processos judiciais concernentes ao tema que foram analisados. A técnica de pesquisa, por fim, desdobra-se em bibliográfica e jurisprudencial.

Quanto à sua estrutura, o presente artigo foi dividido em três partes: a primeira trata sobre o direito à saúde no contexto da Constituição de 1988 e o processo que levou à sua positivação; a segundo analisa a dupla dimensionalidade do direito sanitário, ao se considerar seu caráter positivo e seu caráter negativo; e, por fim, a terceira parte traz um breve estudo acerca das Testemunhas de Jeová e as regras internas do grupo no que se refere à transfusão de sangue, apresenta fundamentos acerca da legitimidade da recusa da transfusão e disserta sobre o dever prestacional do Estado em relação ao procedimento.

\section{DIREITO FUNDAMENTAL À SAÚDE NA CONSTITUIÇÃO DE 1988}

Internacionalmente, a saúde é prevista como direito fundamental, pelo menos desde 1946, com a Constituição da Organização Mundial da Saúde (OMS), que declara que "gozar do melhor estado de saúde que é possível atingir constitui um dos direitos fundamentais de todo o ser humano, sem distinção de raça, de religião, de credo político, de condição econômica ou social" (OMS, 1946). A Declaração Universal dos Direitos Humanos, por sua vez, dois anos depois, também previa que "toda a pessoa tem direito a um nível de vida suficiente para lhe assegurar e à sua família a saúde e o bem-estar [...] (BRASIL, 2013).

Já o Pacto Internacional de Direitos Econômicos, Sociais e Culturais, em 1966, reconhece o direito de toda pessoa desfrutar o mais elevado nível possível de saúde física e mental (BRASIL, 2013). Também a Convenção Americana de Direitos Humanos, embora não arrole a saúde como direito, protege, em seu artigo 5으, a integridade psicofísica (BRASIL, 2013). O Protocolo de São Salvador, por sua vez, dedicou todo seu artigo 10 para dispor sobre o direito à saúde, num sentido bastante amplo (BRASIL, 2013).

No que concerne ao Direito brasileiro, as Constituições Brasileiras que antecederam a de 1988, por exemplo a de 1824 e a de 1891, nem mesmo mencionavam o tema relativo à saúde, embora na Constituição de 1824 a ideia de seguridade social já estivesse presente, ao prever, no artigo 179, que "a Constituição também garante os soccorros públicos" (BRASIL, 1824).

As posteriores (de 1937, 1946, 1967 e a EC 1/1969) atêm-se a anunciar normas de competência concernentes ao poder de legislar sobre normas de saúde. No entendimento de Sarlet e Figueiredo (2008): 


\section{Democracia}

Humanos e

A proteção constitucional existente no país antes de 1988 limitava-se, ou a normas esparsas, como a garantia de "socorros públicos" e a garantia de inviolabilidade do direito à subsistência; ou a normas de distribuição de competências, legislativas e executivas; ou, ainda, a formas indiretas de proteção, quando a saúde integrava os direitos do trabalhador e as normas de assistência social.

Assim, foi tão somente com a Constituição de 1988 que a saúde aparece, finalmente, no rol de direitos fundamentais. Antes disso, a saúde "pública" era restrita aos contribuintes do Instituto Nacional de Previdência Social. Tinha, pois, caráter contributivo, sem acesso universal nem igualitário, pelo menos não nos termos como acontece hoje.

Essa evolução foi fruto de um longo processo de lutas travadas pelo movimento sanitarista no país. Para ilustrar esse movimento com sua história mais recente, deve-se falar da 8 $^{a}$ Conferência Nacional de Saúde, realizada em 1986, pelo Ministério da Saúde em parceria com o Ministério da Previdência e Assistência Social. Nela foi lançada a proposta de reformulação do Sistema Nacional de Saúde, com a separação entre previdência social e saúde. Aquela deveria se encarregar das ações próprias da seguridade social, enquanto esta última "estaria entregue, em nível federal, a um único órgão, com características novas" (BRASIL, 1986). Ademais, outra importante "semente" lançada nesse evento foi a afirmação do direito à saúde como garantia, pelo Estado, "de condições dignas de vida e de acesso universal e igualitário às ações e serviços de promoção, proteção e recuperação de saúde, em todos os seus níveis, a todos os habitantes do território nacional." Também se advogou que o direito à saúde implica garantir o direito à liberdade, à livre organização e expressão, temas pertinentes para o presente trabalho (BRASIL, 1986).

Posteriormente, a partir das teses levantadas na 8a Conferência, formou-se a Comissão Nacional da Reforma Sanitária (CNRS), que "conseguiu elaborar uma proposta de conteúdo de Saúde para a nova Constituição e um projeto de conteúdo para a nova Lei do Sistema Nacional Único de Saúde" (RODRIGUES NETO, 2003, p. 50). Tal comissão ficou responsável pela construção de propostas relativas ao tema sanitário para o novo texto constitucional, consoante aspectos centrais assim considerados pela $8^{\text {a }}$ Conferência e que, portanto, deveriam estar presentes no novel texto constitucional, como a concepção de saúde relacionada ao trabalho, salário, alimentação, habitação, transporte, meio ambiente, etc.; o direito universal e igualitário; o dever de promoção, proteção e recuperação da saúde, pelo Estado; a gratuidade dos serviços de saúde e a desvinculação da Previdência Social (RODRIGUES NETO, 2003, p. 54).

Foi nessa esteira que a discussão do movimento sanitarista chegou na Assembleia Constituinte de 1987-88, tendo sido agrupada na Subcomissão de Saúde, Seguridade e Meio Ambiente que compunha, por sua vez, a Comissão da Ordem Social. Segundo Eleutério Rodrigues Neto (2003), as propostas encaminhadas aos constituintes englobam: i) as derivadas da 8 Conferência e as apresentadas pela CNRS e por outras entidades públicas ou com interesse público; ii) as que defendiam a prática liberal e a iniciativa privada; iii) as institucionais, sobretudo advindas dos ministros da Saúde e da Previdência Social.

Ainda, segundo o mesmo autor, as considerações provindas da $8^{a}$ Conferência e as feitas pela CNRS e demais entidades, foram extremamente convergentes e as únicas que apresentaram propostas ao texto constitucional propriamente ditas. Posteriormente, na formulação do relatório e do anteprojeto referentes à Subcomissão de Saúde, Seguridade e Meio 
Ambiente, tiveram assessores ligados ao movimento sanitarista e suas propostas foram muito bem representadas no anteprojeto aprovado (RODRIGUES NETO, 2003, p. 64), o que parece evidenciar grandes avanços, pelo menos no âmbito legislativo, obtidos no setor da saúde.

O processo de reivindicação pela abrangência e maior efetividade do direito à saúde, que culminou em sua positivação na Constituição de 1988, sob forte influência do movimento sanitário, é assim resumido por Sarlet e Figueiredo (2008):

A explicitação constitucional do direito fundamental à saúde, correlacionado, embora não subsumido, à garantia de assistência social, bem como à criação do Sistema Único de Saúde, viriam com a nova ordem jurídica inaugurada pela CF, que, nesse aspecto, acolheu grande parte das reivindicações do Movimento de Reforma Sanitária. Essa influência é visível, por exemplo: a) na conformação do conceito constitucional de saúde à concepção estabelecida pela Organização Mundial da Saúde (OMS), em que a saúde é compreendida como o estado de completo bem-estar físico, mental e social; b) no alargamento do âmbito de proteção constitucional, ultrapassando a noção meramente curativa de saúde [...] c) na institucionalização de um sistema único, [...] d) na garantia de universalidade e igualdade de acesso à assistência à saúde; e) no estabelecimento da relevância pública das ações e dos serviços de saúde; f) na submissão do setor privado às normas do sistema público de saúde.

Desse modo, tem-se que a Constituição promulgada em 1988, que inaugurou uma nova ordem jurídica, social e econômica no Brasil, ao garantir, por exemplo, um amplo rol de direitos e garantias fundamentais, nos quais se incluem os direitos sociais, abriu caminho para a construção de políticas públicas que tratassem a saúde de forma mais democrática, garantindo-Ihe acesso universal e igualitário, ipsis literis. Por esse mesmo motivo, porém, por se falar de uma inovação no ordenamento, a efetivação ao direito fundamental à saúde traz muitos desafios, inclusive acerca da compreensão de seu caráter, sobre o qual se vai buscar discorrer em seguida.

\section{AS “POSIÇÕES JURÍDICAS” DO DIREITO À SAÚDE}

Até aqui pode-se compreender que o direito sanitário foi uma das grandes inovações (sociais) da Constituição atual. Como, entretanto, já afirmado, pela novidade de que se trata ele, tanto a doutrina quanto a jurisprudência deparam-se com certas dificuldades quando o assunto é saúde, razão pela qual se considera que tal direito ainda se encontra "em construção".

Para ilustrar, já no eixo que visa a tratar este trabalho, há a questão concernente ao status negativo do direito à saúde. Isto porque, tradicionalmente, classsificam-se os direitos fundamentais em dimensões (ou, antes, em gerações), de acordo com critérios cronológicos e das proteções que eles asseguram ao indivíduo. Assim, brevemente, existem os direitos de liberdade ou de primeira dimensão, aos quais se atribui um status negativo, de defesa; também os direitos sociais ou de segunda dimensão, a que se confere o caráter positivo, de prestação - e nos quais costuma-se enquadrar a saúde. Há, ainda, os de terceira dimensão, os difusos e os coletivos, além de uma gama de outras dimensões e classificações que tem sido feita pela doutrina. 


\section{Humanos e \\ Democracia}

Esse tipo de categorização dos direitos fundamentais, todavia, tem encontrado pertinentes críticas. Para Jorge Reis Novais (2010), por exemplo, quando a Constituição prevê certo direito (pretensão, dever ou obrigação) como fundamental ele impõe-se aos poderes constituídos de forma vinculante, e já não importa o nome que lhe é dado. Para o autor português:

Deve ou não um determinado interesse público fazer ceder uma certa faculdade do exercício de um direito fundamental, está ou não o Estado obrigado a uma certa prestação num caso concreto, deve ou não um particular ser compensado pela afectação negativa de uma possibilidade concreta de acesso a um bem fundamental? É isso que importa [...] Ora, para tanto, é absolutamente irrelevante saber se a doutrina integra aquela faculdade, aquele direito ou dever preciso num direito de liberdade, considerado como um todo, ou num direito social (p. 265).

Novais (2010), seguindo essa linha de superação à classificação tradicional, que impede, por exemplo, que os direitos de liberdade também tenham um viés de prestação ou, ainda, que os direitos sociais tenham uma perspectiva defensiva, afirma que é mais comum que os direitos negativos apareçam mais nos direitos de liberdade do que nos sociais. Defende, entretanto, que isso não se trata de uma verdade universal. Insiste, inclusive, que é equívoco que se entendam os direitos sociais tão somente pelo domínio da ajuda estatal, de modo a negligenciar "todos os efeitos de proteção jurídica de que os particulares beneficiam por força da natureza jusfundamental" de tais direitos (NOVAIS, 2010, p. 312).

Dessa forma, Novais (2010) considera que qualquer ação do Estado que interfira negativamente na esfera de proteção dos direitos sociais relativa a um indivíduo ou a um grupo, trata-se de uma restrição a direito fundamental, assim como ocorre com os chamados direitos de liberdade. Insiste, na mesma esteira, que a atuação estatal que afete negativamente a integridade física, seja considerada intervenção restritiva a um direito fundamental; "por que razão não deveríamos ou poderíamos fazer o mesmo quando o legislador, a administração ou o juiz afectam negativamente o acesso individual até aí garantido ao bem saúde, o direito à protecção da saúde?" De forma ainda mais veemente, o autor continua questionando o porquê de inventar quando à dogmática mais convém simplificar (NOVAIS, 2010, p. 313).

Pensamento próximo de Jorge Reis Novais é aquele defendido por Sandra Fredman (2010), para quem a mesma dimensão defensiva dos direitos negativos, que repele a ingerência estatal indevida, a qual é característica dos direitos de liberdade, pode ser identificada nos direitos sociais:

Um padrão semelhante surge em relação aos deveres positivos. Nem todos os direitos socioeconômicos geram deveres positivos. $O$ direito à moradia inclui o dever negativo de não despejar ilegalmente; e o direito à educação inclui o dever de não interferir nos direitos dos pais para assegurar que tal educação esteja em conformidade com suas próprias religiões e convicções filosóficas (tradução nossa).

Vê-se, assim, que, para a professora de Direito de Oxford, os direitos sociais aproximam-se dos direitos de liberdade quando não exigem apenas serviços de assistência e de prestação, mas, da mesma forma, protegem o indivíduo contra a atuação indesejada do Estado em sua vida. Evidencia-se, pois, em relação aos direitos sociais, outra dimensão, qual seja, a de defesa. 
Pelo que foi exposto, entretanto, acerca da historicidade do direito sanitário, com base no que a doutrina diz sobre sua positivação, bem como sobre o processo que levou a ela, pode-se notar que, ao que parece, a ideia geral do movimento sanitarista e do constituinte era atribuir a tal direito um caráter de prestação, haja vista que o próprio artigo 196 da Constituição fala em "promoção, proteção e recuperação" da saúde, mas não alude, por exemplo, à sua defesa contra intervenções do Estado ou de terceiros. Nesse ponto, compreende-se que a ciência e a aplicação do direito não devem se ater à mens legislatoris, o que consistiria um grande equívoco.

Há, também, que se interpretar o direito fundamental à saúde não mais com o mero intuito prestacional que predominava à época de sua positivação, mas já com todas as dimensões que lhe cabem, inclusive a de caráter defensivo. Nessa linha, considera-se pertinente a observação da teoria dos quatro "status" de Georg Jellinek (status positivo, status negativo, status passivo e status ativo), a qual vem sendo aplicada quanto aos direitos fundamentais. $O$ negativo (status negativus ou status libertatis), que mais interessa, consagra ao indivíduo um âmbito de liberdade que deve estar isento da interferência do Estado. Exigem, dessa forma, "uma posição de respeito e abstenção por parte dos poderes públicos" (MENDES; BRANCO, 2012, p. 888).

O entendimento de que o direito sanitário inclui uma gama de posições jurídicas - e não apenas aquela que corresponde à sua dimensão prestacional - encontra respaldo na doutrina brasileira, vide, por exemplo, o posicionamento de Ingo Sarlet e Mariana Figueiredo, nas considerações sobre os 20 anos da Constituição de 1988:

Outrossim, deve-se assinalar que o direito fundamental à saúde envolve um complexo de posições jurídico-subjetivas diversas quanto ao seu objeto, podendo ser reconduzido às noções de direito de defesa e de direito a prestações. Como direito de defesa (ou direito negativo), o direito à saúde visa à salvaguarda da saúde individual e da saúde pública contra ingerências indevidas, por parte do Estado ou de sujeitos privados, individual e coletivamente considerados (SARLET; FIGUEIREDO, 2008, p. 9)

Em estudo diverso, Sarlet (2007) não somente defende, mas explana acerca da dimensão negativa do direito à saúde, que ele também chama de "saúde como direito de defesa". Para ele, nesse âmbito, a dimensão negativa abrange o princípio da proibição de retrocesso, além da própria caracterização da saúde enquanto cláusula pétrea pela Constituição de 1988, de modo que uma emenda constitucional não pode "impor restrições desproporcionais e/ou invasivas do núcleo essencial do direito à saúde". Essa dimensão negativa, ademais, protege a saúde do indivíduo, consagrada como bem jusfundamental, de qualquer agressão de terceiros, inclusive do Estado. Assim, para o jurista gaúcho, "qualquer ação do poder público (e mesmo de particulares) ofensiva ao direito à saúde é, pelo menos em princípio, inconstitucional [...]" (SARLET, 2007, p. 10).

Por conseguinte, é nesse cenário que se busca identificar, definitivamente, uma "multidimensionalidade" do direito à saúde, que possa admitir que a saúde, como bem jurídico protegido em sede de direitos fundamentais, não inclui tão somente o indiscutível caráter de prestação, o que consistiria numa visão limitada da complexidade que o direito sanitário pode abranger. Tal perspectiva tampouco cumpriria o fim que se considera último da Constituição, que é proteger a dignidade da pessoa humana - ao proteger, nesse sentido, sua vida e sua saúde. 


\section{Humanos e \\ Democracia}

\section{AS TESTEMUNHAS DE JEOVÁ: RELIGIÃO, SAÚDE E DIREITOS}

\subsection{Breve histórico}

Em síntese que se entende necessária, apresenta-se o grupo das Testemunhas de Jeová como uma religião (e não como uma seita) de denominação cristã não trinitária, milenarista e restauracionista, com 8.457.107 de adeptos estimados em 240 países (sic) e reunidos em 120.053 congregações, segundo o próprio site oficial em português. ${ }^{1}$

Seus primórdios remontam à década de 1870, quando Charles Taze Russell, natural da Pensilvânia, nos Estados Unidos, insatisfeito com as religiões até então existentes, criou um grupo de estudos bíblicos e, posteriormente, passou a fazer publicações em periódicos, por meio da revista "Watch Tower", chamada, em português, de "A Sentinela" (PEDRINI; SILVA, 2015).

O grupo, fundado por Russel, passou a ser chamado de "Testemunhas de Jeová" a partir de 1931, e é conhecido mormente por suas atividades de pregação e proselitismo em residências particulares e logradouros públicos. Além disso, "não costumam intervir em questões ou atividades políticas, não apoiam as guerras ou qualquer forma de violência, e evitam a embriaguez, o fumo e as drogas" (BRASIL, 2017).

Por sua interpretação peculiar da Bíblia, as Testemunhas de Jeová entendem que a hemotransfusão é proibida, uma vez que o sangue contém a alma do ser vivo. Para eles, "o mais importante é que Deus nos manda nos abster do sangue porque ele representa a vida, que é algo sagrado para Deus." ${ }^{2}$

A vedação das transfusões sanguíneas baseia-se em trechos bíblicos dos livros de Gênesis, Levítico e Atos dos Apóstolos que, pela versão da Bíblia adotada pelas Testemunhas de Jeová e traduzida para o português, dizem, in verbis:

Todo animal que se move e que está vivo pode servir-lhes de alimento. Assim como dei a vocês a vegetação verde, eu lhes dou todos eles. Somente não comam a carne de um animal com seu sangue, que é a sua vida (GÊNESIS 9, 4, BÍBLIA SAGRADA, 2015).

O livro do Levítico, por sua vez, é ainda mais enfático quanto à questão de o sangue conter a vida e a alma:

Pois a vida de uma criatura está no sangue, e eu mesmo o dei a vocês para que façam expiação por si mesmos no altar. Pois é o sangue que faz expiação por meio da vida que está nele. [...] Pois a vida de todo tipo de criatura é seu sangue, porque a vida está no sangue. Por isso eu disse aos israelitas: "Não comam o sangue de nenhuma criatura, porque a vida de todas as criaturas é seu sangue. Quem o comer será eliminado (LEVÍTICO 17, 11.14, BÍBLIA SAGRADA, 2015).

Por fim, já no Novo Testamento, o livro de Atos manda que os cristãos "se abstenham de coisas contaminadas por ídolos, de imoralidade sexual, do que foi estrangulado e de sangue" (ATOS 15, 20, BÍBLIA SAGRADA, 2015). Desse modo, é de acordo com os trechos bíbli-

\footnotetext{
Disponível em: https://www.jw.org/pt/testemunhas-de-jeova. Acesso em: 5 ago. 2018.

O que a Bíblia diz sobre transfusões de sangue? Disponível em: https://www.jw.org/pt/ensinos-biblicos/perguntas/bibliatransfusoes-de-sangue/\#?insight[search_id]=7a732200-d3ba-4f06-8eec-6d6430db4565\&insight[search_result_index]=7. Acesso em: 5. ago. 2018.
} 
cos supratranscritos que a transfusão de sangue é entendida como uma grave falta contra Deus e seus mandamentos por parte das Testemunhas de Jeová, e que deve, portanto, ser evitada.

Reitera-se, além disso, que essa proibição refere-se aos diversos elementos componentes do sangue, como as hemácias, os leucócitos, o plasma e as plaquetas, além, é claro, da transfusão de sangue previamente estocado. Não inclui, todavia, de forma absoluta, pequenas frações que integram o tecido sanguíneo, como as imunoglobulinas, a albumina, o fibrinogênio e os fatores de coagulação para hemofilia (NERY JUNIOR, 2014, p. 21).

\subsection{A questão jurídica da recusa da transfusão de sangue}

Embora os conceitos jurídicos de legalidade e de legitimidade sejam muito próximos, eles não se confundem, uma vez que:

[...] o conceito normativo da legitimidade política refere-se a algum ponto de referência de aceitação ou justificação do poder político ou de autoridade. Assim, segundo John Rawls (1993), a Legitimidade é explicada por que o uso do poder político por uma determinada instituição (Estado, Governo, alguma coletividade) é permitido, havendo, como consequência, o dever moral de obedecer seus comandos [...]. Em um entendimento mais estrito desta última interpretação, a legitimidade está relacionada com a justificação moral da autoridade política e não com a sua criação (MIRANDA NETO; PEREIRA, 2014).

Desse modo, entende-se que, ao se discutir a legitimidade da recusa da hemotransfusão por parte do grupo das Testemunhas de Jeová, fala-se sobre a existência de motivos razoáveis e admitidos pela lei e pelo direito que justifiquem essa escolha. Trata-se, pois, em última instância, da justificação da recusa.

O tema é polêmico e sobre ele há entendimentos diversos apoiados em variados dispositivos legais, uma vez que, de forma geral, não se pode afirmar que há uma norma jurídica, no Brasil, que regule o assunto com abrangência nacional de forma definitiva. Assim, o que existem são normativas esparsas e genéricas, por exemplo, a Resolução CFM no 1.021/80, que considera que "a recusa do paciente em receber a transfusão sangüínea, salvadora de sua vida, poderia, ainda, ser encarada como suicídio" (sic) e que conclui:

Em caso de haver recusa em permitir a transfusão de sangue, o médico, obedecendo a seu Código de Ética Médica, deverá observar a seguinte conduta: 10 - Se não houver iminente perigo de vida, o médico respeitará a vontade do paciente ou de seus responsáveis. 2ㅇ- - Se houver iminente perigo de vida, o médico praticará a transfusão de sangue, independentemente de consentimento do paciente ou de seus responsáveis (CFM, 1980). ${ }^{3}$

No que se refere à assertiva do CFM de que a recusa à transfusão consistiria em suicídio, trata-se de um argumento recorrente apresentado contra a recusa dos grupos das Testemunhas de Jeová. Esta alegação, todavia, é rebatida por Nery Junior (2014), para quem a negatória de tal grupo não pode jamais ser equiparada ao suicídio, uma vez que o paciente Testemunha de Jeová busca tratamento e almeja a cura, contanto que não seja via hemotransfusão.

\footnotetext{
3 Revogada pela Resolução CFM 2.232/2019. Disponível em: https://sistemas.cfm.org.br/normas/visualizar/resolucoes/ BR/2019/2232 Acesso em: 31 jul. 2020.
} 


\section{Democracia}

Humanos e

Da mesma forma, é válido destacar que a responsável pela Procuradoria Federal dos Direitos do Cidadão (PFDC), Deborah Duprat, apresentou, no ano de 2017, um pedido à Procuradoria-Geral da República no sentido de se propor Arguição de Descumprimento de Preceito Fundamental (ADPF), a fim de se declarar a inconstitucionalidade de tal normativa. 0 entendimento da PFDC também está em consonância com o que ensina Nelson Nery Junior (2014), que defende a inconstitucionalidade de tal resolução "uma vez que, submete o cidadão a tratamento médico contra sua própria vontade em frontal desrespeito à sua dignidade (CF, 1ㅇ, III) e à sua liberdade (CF, 5으, caput), e nos casos dos praticantes da religião Testemunhas de Jeová, também à sua liberdade de crença (CF, 5ㅇ, VI)", além de contrariar o que está previsto no artigo 70, III e $\mathrm{V}$ da Lei 8.080/1990, que impera que os procedimentos públicos de saúde, ligados ou não ao Serviço Único de Saúde (SUS), devem obedecer aos princípios da autonomia das pessoas na defesa de sua integridade física e moral e do direito à informação às pessoas assistidas.

O pedido formulado pela PFDC, igualmente, cita uma pesquisa formulada pela Procuradoria Regional dos Direitos do Cidadão do Rio de Janeiro junto a instituições sanitárias. Em tal estudo, restou demonstrado que a maioria dos profissionais da saúde realiza a hemotransfusão, ainda que contra a vontade do paciente, em caso de risco de morte, com embasamento na Resolução número 1.021/1980.

Ressalta-se que a solicitação apresentada pela PFDC tem os objetivos de declarar que: i) praticar a transfusão de sangue sem o consentimento do paciente, mesmo em caso de risco iminente de vida, somente é permitido quando se tratar de criança, adolescente ou pessoa incapaz, por qualquer motivo, de exprimir a própria vontade; ii) é vedada intervenção médica (inclusive hemotransfusão), contra a vontade do paciente, mesmo em hipótese de risco de morte. O pedido da PFDC também requer que se confira interpretação conforme à Constituição iii) à Resolução no 1.021/80 do CFM, no sentido de que esta só se aplica quando se tratar de criança, adolescente, ou pessoa incapaz de exprimir a própria vontade e iv) ao artigo $146 \S$ 3o, I do Código Penal, para se afirmar que tal previsão legal não autoriza intervenção médica quando houver manifestação contrária do paciente adulto e capaz (BRASIL, 2017).

De fato, o Código Penal, ao tipificar o constrangimento ilegal, excetua a intervenção médica ou cirúrgica sem o consentimento do paciente ou de seu representante, quando esta se justificar pelo iminente risco de morte. O Código de Ética Médica (CEM), por sua vez, não dispõe de forma detalhada acerca do procedimento de transfusão de sangue. Já em sua introdução, entretanto, tal codex fala "na proibição de que [o médico] deixe de obter o consentimento do paciente ou de seu representante legal após esclarecê-lo sobre o procedimento a ser realizado, salvo em iminente risco de morte" (CFM, 2009). Além disso, em seu artigo 22, o CEM (CFM, 2009) declara ser proibido ao médico "deixar de obter consentimento do paciente ou de seu representante legal após esclarecê-lo sobre o procedimento a ser realizado, salvo em caso de risco iminente de morte" (grifo nosso).

Esclarece-se que o CEM (CFM, 2009), agora em seu artigo 24, veda ao médico "deixar de garantir ao paciente o exercício do direito de decidir livremente sobre sua pessoa ou seu bem-estar, bem como exercer sua autoridade para limitá-lo". O que está disposto no artigo 22, todavia, parece ser uma limitação ou uma exceção ao artigo 24, pelo menos é o que entende Nelson Nery Junior (2014), e com quem estamos de acordo. 
Por outro lado, invoca-se o enunciado do artigo 5o da Portaria 1.820/2009 do Ministério da Saúde, que, embora também tenha aplicação em âmbito federal e sirva como forte embasamento para a legitimidade da recusa da hemotransfusão, tampouco trata dela diretamente. Essa portaria, que dispõe sobre os direitos e deveres dos usuários da saúde, prevê, in verbis, que:

Art. 5 o Toda pessoa deve ter seus valores, cultura e direitos respeitados na relação com os serviços de saúde, garantindo-Ihe:

$[\ldots]$

V - o consentimento livre, voluntário e esclarecido, a quaisquer procedimentos diagnósticos, preventivos ou terapêuticos, salvo nos casos que acarretem risco à saúde pública, considerando que o consentimento anteriormente dado poderá ser revogado a qualquer instante, por decisão livre e esclarecida, sem que sejam imputadas à pessoa sanções morais, financeiras ou legais (BRASIL, 2009).

Embora, no entanto, considere-se que a legislação infraconstitucional não apresenta uma solução definitiva para o problema da transfusão sanguínea, tem-se que a Constituição define a dignidade da pessoa humana como fundamento da República, além de afixar os direitos à vida e à liberdade no rol de direitos fundamentais de seu artigo 5․ Complementarmente, a partir do foco deste trabalho, o texto constitucional também consagra a saúde como direito fundamental, por ser ela corolário da dignidade, da vida e da integridade psicofísica, além de pré-requisito inexorável para o gozo desses e de quaisquer outros direitos. Nesse sentido, Sarlet e Figueiredo (2008) defendem a dupla fundamentalidade do direito à saúde, haja vista que um sistema jurídico-constitucional "que protege o direito à vida e assegura o direito à integridade física e corporal, evidentemente, também protege a saúde, já que onde esta não existe e não é assegurada, resta esvaziada a proteção prevista para a vida e integridade física" (p. 3).

De modo geral, costumam-se apresentar três entendimentos doutrinários diferentes sobre o tema, os quais afirmam que: i) o direito à vida é absoluto e a transfusão deve ser realizada ainda que a contragosto do paciente, independentemente do motivo; ii) a hemotransfusão só deve ser realizada sem o consentimento do paciente ou contra sua vontade em caso de risco de morte; iii) a liberdade do paciente deve prevalecer (PEDRINI; SILVA, 2015).

Quanto à primeira corrente, sabe-se, a priori, que não existem, no ordenamento brasileiro, direitos com caráter absoluto. É esse, por exemplo, o entendimento das autoras Pedrini e Silva (2015, p. 47), apoiando-se no recente entendimento do STF e de Letícia de Campos VeIho Martel. Ademais, a restrição do direito à vida pode ser constatada na legalidade do aborto resultante de estupro e no homicídio em legítima defesa. Advoga-se, portanto, que a alegação médico-jurídica de que a vida se sobrepõe a qualquer outro direito - e que deve ser preservada inclusive por meios com que o paciente discorda - é inválida.

Em relação à segunda corrente, de que, em risco iminente de morte, admite-se a transfusão, ainda que sem o consentimento do paciente ou contra sua vontade, há que se destacar, primeiramente, que a hemotransfusão não consiste num tratamento infalível e plenamente eficaz, que seguramente garantirá o reestabelecimento do paciente. Tampouco é tratamento único, haja vista que podem haver (e muitas vezes, de fato há) alternativas terapêuticas à transfusão. Além disso, como explica muito bem Deborah Duprat: 


\section{Democracia}

[...] o desejo de viver não supera a vontade de não transgredir os princípios doutrinais de seu credo religioso. Não havendo alternativas terapêuticas de eficácia e segurança equivalentes à transfusão de sangue ou de seus derivados, a sua recusa frente ao risco iminente de vida consiste, ainda que de modo indireto, em uma resignação ante à eventualidade de morte superveniente, por crerem envolvidos bens espirituais e morais ante aos quais, levando-se em conta a totalidade de sua pessoa, o bem corpóreo acaba por ceder. Há que se destacar, portanto, que não se trata de algo supérfluo ou irrelevante, senão um dogma que se constitui em componente central das crenças que definem a própria religião das testemunhas de Jeová, especialmente por envolver o que pensam sobre a vida após a morte [...] (BRASIL, 2017, p. 7).

Em outra linha, entende-se que o ordenamento não repele de forma brutal e absoluta o risco de morte. É o que defende Luís Roberto Barroso (2010, p. 22), quando afirma que "o Estado não pode proibir alguém de prestar ajuda humanitária em uma região de guerra, ou de praticar esportes radicais, ainda que o risco seja elevado ao extremo". Para o atual ministro do STF, em relevante parecer sobre o tema, trata-se de escolhas existenciais cuja legitimidade deriva da conciliação entre o valor objetivo da vida e as liberdades decorrentes da dignidade da pessoa humana enquanto autonomia.

No concernente à terceira corrente - a que defende a prevalência do direito à liberdade - entende-se como a mais acertada. Também advoga-se, entretanto, que não se trata somente de uma questão de liberdade, sobremodo de liberdade religiosa, mas, principalmente, de saúde, entendida em seu viés negativo, que protege o indivíduo de interferências estatais indevidas.

Numa outra esteira, já de modo a superar o aparente conflito entre as três correntes apresentadas, Nelson Nery Junior vai além, ao afirmar que inexistem colisões reais entre direitos fundamentais quando se fala em recusa à transfusão de sangue por parte das Testemunhas de Jeová. Para o ilustre autor, embasando-se nas teorias de Robert Alexy sobre os direitos fundamentais, estes podem colidir ampla ou restritivamente. A colisão, em sentido restrito, ocorreria quando o exercício dos direitos fundamentais de um indivíduo repercutisse negativamente sobre os direitos fundamentais de outro sujeito. Quanto a essa hipótese, Nery Junior (2014, p. 10) afirma que quando uma Testemunha de Jeová recusa-se a receber a transfusão de sangue "ele invoca seus direitos fundamentais, conduta esta que em nenhuma hipótese atenta contra direito fundamental de outrem. Afinal, qual direito fundamental de outrem essa recusa pelo paciente Testemunha de Jeová violaria?"

A colisão em sentido amplo, por sua vez, caracteriza-se como o conflito entre o exercício dos direitos fundamentais de um determinado sujeito titular deles e bens coletivos, no caso, entre a liberdade e a saúde do indivíduo Testemunha de Jeová e a vida e a saúde pública. Para o autor, entretanto, tal argumento não se configura no caso, uma vez que "o indivíduo pertencente a essa religião, quando recusa tratamento que envolva a transfusão sanguínea, em nenhum momento recusa-se a se submeter a outras opções terapêuticas médicas, ou seja, o paciente Testemunha de Jeová não deseja a morte, bem como não acredita na cura pela fé" (NERY JUNIOR, 2014, p. 11).

Por conseguinte, entende-se que não há que se falar em colisão de direitos fundamentais na hipótese de recusa de Testemunhas de Jeová em receberem transfusão de sangue. Essa negatória diz respeito não somente à liberdade e à intimidade do indivíduo, mas mor- 
mente à sua saúde e ao direito que ele tem de repelir decisões e ingerências estatais mal-vindas - o que caracteriza, como é defendido nesse trabalho, a dimensão negativa do direito à saúde.

Isto porque, no estudo do direito à saúde, classificado pela doutrina como direito social, mas, antes de tudo, como direito fundamental, e assim garantido pela Constituição, há que se ter em mente que não se resume ele a mera faculdade do cidadão de exigir prestações do Estado. Como quaisquer outros direitos sociais, o direito à saúde deve ser considerado em relação à sua dimensão positiva, mas também por sua dimensão negativa, isto é, respectivamente, direitos a um facere ante o Estado e, igualmente, direitos a um non facere. Esta segunda dimensão, a negativa, assegura que "o Estado não interfira ou não afete negativamente o acesso já garantido, subjectivizado ou não, fáctico ou jurídico, a tais bens, e quer se trate de acesso que o particular obteve por meios próprios ou através da ajuda estatal" (NOVAIS, 2010, p. 239).

Jorge Reis Novais (2010, p. 257) é ainda mais enfático ao afirmar que os direitos fundamentais - os de liberdade, assim como os sociais - devem ser considerados como um todo, como uma unidade, e concebidos a partir de três deveres que exigem ao Estado: o de respeito, o de proteção e o de promoção. Os deveres estatais de respeito e de proteção aos direitos fundamentais nada mais são do que, respectivamente, o dever de não interferência na esfera autônoma do sujeito de direitos e o dever de proteção contra ameaças ou agressões, além do evitamento de riscos. Esses deveres, reitera-se, valem, inclusive, contra o próprio Estado.

Desse modo, aplicando a teoria do autor português ao direito à saúde e, mais precisamente, no caso da recusa de transfusão de sangue por Testemunhas de Jeová, advoga-se, nesse sentido, de que a dimensão negativa do direito à saúde e o dever estatal de respeito, exigem que o Estado acate a decisão do indivíduo de não receber a hemotransfusão. Por lógica, se o Estado ou terceiro (como hospitais e profissionais da saúde) insistem em transfundir sangue sem o consentimento do indivíduo ou contra sua vontade, ainda em caso de risco de morte, há claramente um desrespeito ao direito à saúde.

Em relação à proteção contra agressão e ameaça de agressão de terceiros, a construção doutrinária de Sarlet $(2007$, p. 8) confirma esse entendimento, qual seja, de que a dimensão negativa do direito à saúde inclui a defesa desta contra ingerências de terceiros.

Também se chama a atenção para o fato de que se exige o consentimento do paciente para que a transfusão seja efetuada nos termos do artigo 5ㅇ, V, da Portaria 1.820/2009 do Ministério da Saúde. Esse consentimento, segundo a normativa, deve ser livre, voluntário e esclarecido, requisitos indispensáveis para que se caracterize como um consentimento genuíno, como entende Luís Roberto Barroso (2010, p. 31).

Quanto à responsabilidade dos médicos, de uma perspectiva jurídico-penal, a ausência de tipicidade da conduta médica sustenta-se na ausência dos elementos dos tipos penais, sobretudo aqueles que visam à proteção dos bens jurídicos vida e integridade física, haja vista que o médico em nada contribuiu para o aumento do risco ou para a causa do resultado. Não bastasse, é preciso salientar que a recusa informada ao procedimento terapêutico configura verdadeira autocolocação em perigo, tendo em vista que o paciente que se nega a receber transfusão de sangue participa conscientemente do resultado protegido juridicamente com sua própria conduta. A doutrina da autocolocação em perigo, que se presta, sobretudo, para 


\section{Democracia}

Humanos e

afastar a responsabilidade de terceiros pela ocorrência do resultado, foi aplicada pelo Superior Tribunal de Justiça no Habeas Corpus n. 46.525 - MT -, julgado em 21 de março de 2006, caso em que uma pessoa se afogou após ter ingerido substâncias psicotrópicas e ter sido laçada à piscina pelos membros da comissão de formatura - a conduta destes foi considerada atípica em razão da autocolocação em perigo, restando ausentes a previsibilidade, o nexo de causalidade e a criação de um risco não permitido em relação a todos os denunciados.

Por fim, no que se refere à transfusão de sangue em menores de idade, entende-se que se trata de um assunto mais específico, uma vez que pode-se alegar a invalidez do consentimento do paciente por sua incapacidade relativa ou absoluta, motivo pelo qual este trabalho, por limitações de espaço, não se propõe a enfrentar tal tema. É importante apresentar, entretanto, que autores como Nelson Nery Junior (2014, p. 29) defendem que o consentimento informado do menor ratificado por seus pais deve ser levado em conta, de modo a não se proceder a um tratamento de saúde contrário à sua vontade. Em sentido contrário, contudo, apresentam seus argumentos Pedrini e Silva (2015, p. 55).

A esse respeito, manifestou-se a Sexta Turma do Superior Tribunal de Justiça em sede do Habeas Corpus n. 268.459 - SP -, julgado em 2 de setembro de 2014, para entender que a recusa dos pais em autorizar a realização do procedimento de transfusão de sangue em filha adolescente, por motivo de crença religiosa, não constitui crime. No caso, os pais conduziram a filha até o hospital para que recebesse assistência médica, sem, todavia, consentirem a realização de hemotransfusão. Se, de um lado, a Corte Superior entendeu que não se configurou omissão de socorro ou homicídio por omissão da parte dos pais, pois que não houve quebra do dever de cuidado, de outro lado, afirmaram os ministros que caberia aos médicos, caso considerassem a medida indispensável para que fosse evitada a morte, a adoção dos procedimentos necessários, não podendo privar a adolescente de os receber. Diante disso, a Corte entendeu que a ausência de autorização dos pais era inócua e que, dada a significância do direito à vida e do superior interesse do adolescente, a adoção das necessárias providências terapêuticas pelo hospital era imperiosa.

\subsection{0 dever prestacional sanitário relativo às Testemunhas de Jeová}

Como já foi apresentado, a recusa das Testemunhas de Jeová em receber transfusão de sangue, mesmo que em hipótese de risco de morte, não pode, como costumeiramente se alega, ser considerada suicídio, ou, quando em caso dos pais de menor, como omissão de socorro ou homicídio doloso. Isto porque: i) a maioria dos casos são referentes a indivíduos que estão internados em hospitais por conta própria, pois procuraram auxílio médico, logo, não se poderia falar em suicídio ou descaso com a própria vida; ii) a transfusão de sangue não é método de eficácia garantida; iii) há tratamentos alternativos.

A utilização de meios terapêuticos alternativos é um dos principais argumentos usados pelas Testemunhas de Jeová em defesa de seu direito de recusar a transfusão. ${ }^{4}$ Entre tais meios, destacam-se a Eritropoetina [Humana] Recombinante, a Interleucina-11 Recombinante, os expansores do volume do plasma e o coagulador com raio de argônio, por exemplo (MARINI, 2005).

\footnotetext{
Alternativas de qualidade para a transfusão. Disponível em: https://www.jw.org/pt/publicacoes/livros/como-pode-osangue/Alternativas-de-qualidade-para-a-transfus\%C3\%A3o/. Acesso em: 9 ago. 2018.
} 
Desse modo, na linha da unidade dos direitos fundamentais defendida por Jorge Reis Novais (2010), tem-se que o direito à saúde é dotado de uma dimensão positiva e de outra negativa, como já explanado. Ocorre que, ao se levar em conta a dimensão negativa do direito sanitário, de forma a se legitimar a recusa da transfusão, tal recusa fica ainda mais "legítima", por assim dizer, quando é possibilitado ao paciente um tratamento alternativo, sobretudo quando ele se mostra eficaz. Entende-se que, nesse caso, o direito fundamental à saúde restará plenamente efetivado.

Há que se questionar, todavia, se é dever do Estado oferecer essas formas alternativas de tratamento. É o que ordena a Portaria 1.820/2009 do Ministério da Saúde, por exemplo, ao dispor que:

40: Toda pessoa tem direito ao atendimento humanizado e acolhedor, realizado por profissionais qualificados, em ambiente limpo, confortável e acessível a todos.

$[\ldots]$

XI: o direito à escolha de alternativa de tratamento, quando houver, e à consideração da recusa de tratamento proposto.

Na mesma esteira da norma supratranscrita, Nery Junior (2014) também defende que o Estado deve oferecer ao paciente Testemunha de Jeová todos os métodos terapêuticos alternativos à transfusão de sangue, de modo a respeitar sua recusa e suas escolhas. Caso contrário, explica o jurista que "a recusa em disponibilizar tratamento médico alternativo às Testemunhas de Jeová caracteriza discriminação contra os adeptos dessa religião, violando os preceitos constitucionais que asseguram a dignidade e liberdade religiosa" (NERY JUNIOR, 2014, p. 31).

Também a douta Procuradora Federal dos Direitos do Cidadão, ao pedir à PGR que propusesse ADPF ante a Resolução 1.021/1980 do CFM, argumenta que, tendo em vista o atual estágio médico-científico, já é possível evitar a hemotransfusão na maioria dos casos por meio da combinação de técnicas e medicamentos. Ademais, para ela, "o Estado investe em um equipamento que poderá servir a qualquer paciente que não deseje se tratar com transfusão de sangue ou eventualmente não possa" (BRASIL, 2017).

Entende-se, portanto, que é dever do Estado não apenas respeitar e proteger o direito sanitário, mas promovê-lo, como ensina Novais (2010). Nesse sentido, a dupla dimensionalidade do direito à saúde exige também que os Poderes Públicos empenhem-se em possibilitar ao paciente Testemunha de Jeová (e a todos os outros) alternativas à transfusão de sangue e condições razoáveis de terem acesso a elas. Tão somente dessa forma, acredita-se, o direito fundamental à saúde estaria efetivado.

\section{CONSIDERAÇÕES FINAIS}

A saúde consiste em direito fundamental, dotada de dupla fundamentalidade, formal e material. Seu ingresso na ordem jurídico-constitucional brasileira deu-se mediante um longo processo, com profundas discussões, com enfoque para as que se realizaram na 8 a Conferência Nacional de Saúde com diversos atores, com destaque para o movimento sanitarista. Por fim, tem-se que foi por meio de importantes e frutíferos debates na Assembleia Constituinte de 1987-88 que tal direito foi definitivamente positivado. 


\section{Democracia}

Humanos e

Pela atualidade do tema (não se deve desprezar o fato de que nossa Constituição foi promulgada há apenas três décadas), o direito sanitário envolve numerosos debates acerca de diversos temas, entre eles sua dupla dimensionalidade. Isto porque, embora a dimensão positiva ou prestacional da saúde receba muito mais atenção, principalmente dos juristas, mas não apenas deles, em razão dos muitos casos de "judicialização da saúde", advoga-se também a existência de uma dimensão negativa, que tem como escopo defender o sujeito titular de direitos fundamentais de intervenções descabidas do Estado. Ou seja, entende-se que há certos limites quanto à atuação estatal quando o assunto é saúde, motivo pelo qual se exige, em alguns casos, sua abstenção.

Um desses casos, aqui explorado, é a recusa do procedimento de transfusão sanguínea pelos adeptos da religião das Testemunhas de Jeová. Enquanto parte da doutrina e da jurisprudência entende haver aí colisão de direitos fundamentais (vida e saúde pública vs. liberdade religiosa, intimidade e saúde individual) e que o direito à vida deve sempre prevalecer, há posicionamentos diversos que defendem a legitimidade da recusa das Testemunhas de Jeová em receber a transfusão. Há, ainda, juristas, como Nelson Nery Junior, que defendem que nem sequer há colisão jusfundamental em sentido estrito ou amplo, uma vez que a negatória deste grupo religioso não ofende nem o exercício de direitos fundamentais de outros indivíduos nem bens coletivos.

No que se refere aos adultos (não se considerando o caso de crianças e adolescentes), alinha-se, aqui, ao posicionamento de Nery Junior, por se entender completamente legítima a recusa à hemotransfusão, uma vez que a dimensão negativa do direito sanitário autoriza a seu titular a repulsão à interferência indevida do Estado ou de terceiros no âmbito de sua saúde. Entende-se, ainda, que esse viés negativo também abriga o indivíduo quanto às escolhas e alternativas do que ele entende mais adequado à sua saúde, e, por óbvio, aos tratamentos, remédios e, inclusive, médicos e hospitais que ele eleger para si. Não se vislumbra, portanto, nenhuma colisão entre direitos fundamentais.

Ao cabo, compreende-se que também é dever do Estado promover formas alternativas de terapia às Testemunhas de Jeová, de modo que estas possam, respeitadas suas crenças, recusar a transfusão sem colocar em risco a própria vida, ou, pelo menos, sem que sejam acusadas disso ou de "suicídio" ou de "tentativa de suicídio", como insinua a própria Resolução $1.081 / 1980$ do CFM. Esse dever estatal, vale frisar, faz parte da promoção do direito fundamental à saúde e deriva de sua dimensão positiva ou de prestação e, desta feita, o Estado não pode dele se eximir.

\section{REFERÊNCIAS}

BÍBLIA SAGRADA. Tradução Associação Torre de Vigia de Bíblias e Tratados. New York, USA: Watch Tower Bible and Tract Society of New York of Pennsylvania, 2015.

BARROSO, Luis Roberto. Legitimidade da recusa de transfusão de sangue por Testemunhas de Jeová. Dignidade Humana, Liberdade Religiosa e Escolhas Existenciais. Parecer Jurídico, Rio de Janeiro, 5 de abril de 2010. Disponível em: https://www.conjur.com.br/dl/testemunhas-jeova-sangue.pdf. Acesso em: 30 jul. 2018.

BRASIL. Conferência Nacional de Saúde, 8. Relatório final. Brasília: Ministério da Saúde, 1986. Disponível em: http://bvsms.saude.gov.br/bvs/publicacoes/8_conferencia_nacional_saude_relatorio_final.pdf. Acesso em: 2 ago. 2018.

BRASIL. Conselho Nacional de Secretários de Saúde. As Conferências Nacionais de Saúde: evolução e perspectivas. Brasília: CONASS, 2009. 
BRASIL. Constituição Política do Império do Brazil. Rio de Janeiro, 1824. Disponível em: http://www.planalto.gov. br/ccivil_03/Constituicao/Constitui\%C3\%A7ao24.htm. Acesso em: 24 jul. 2018.

BRASIL. Constituição da República dos Estados Unidos do Brasil. Diário Oficial da União, Rio de Janeiro, 16 jul. 1934. Disponível em: http://www.planalto.gov.br/ccivil_03/Constituicao/Constitui\%C3\%A7ao34.htm. Acesso em: 24 jul. 2018.

BRASIL. Constituição da República Federativa do Brasil de 1988. Diário Oficial da União, Brasília, 5 out. 1988. Disponível em: http://www.planalto.gov.br/ccivil_03/constituicao/constituicao.htm. Acesso em: 25 jul. 2018.

BRASIL. Direitos humanos. 4. ed. Brasília: Senado Federal; Coordenação de Edições Técnicas, 2013. Disponível em: http://www2.senado.leg.br/bdsf/bitstream/handle/id/508144/000992124.pdf?sequence. Acesso em: 25 jul. 2018.

BRASIL. Superior Tribunal de Justiça. Habeas Corpus número 268.459 - SP (2013/0106116-5). Relatora: Maria Thereza de Assis Moura. Diário de Justiça Eletrônico, Brasília, 6 dez. de 2014. Disponível em: https://ww2.stj. jus.br/websecstj/cgi/revista/REJ.cgi/ITA?seq=1363684\&tipo=0\&nreg=201301061165\&SeqCgrmaSessao=\&CodOrgaoJgdr=\&dt=20141119\&formato=PDF\&salvar=false. Acesso em: 10 ago. 2018.

BRASIL. Supremo Tribunal Federal. Ação Direta de Inconstitucionalidade (ADI) 4.277/DF. Relator: Ayres Britto. Diário de Justiça Eletrônico, Brasília, 5 maio 2011. Disponível em: http://redir.stf.jus.br/paginadorpub/paginador. jsp?docTP=AC\&docID=628635. Acesso em: 2 ago. 2018.

BRASIL. Procuradoria Federal dos Direitos do Cidadão (PFDC). Requerimento Pgr-00152645/2017. 2017. Disponível em: http://pfdc.pgr.mpf.mp.br/atuacao-e-conteudos-de-apoio/temas-de-atuacao/direitos-humanos/atuacao-do-mpf/liberdade-religiosa/representacao-cfm-testemunha-jeova Acesso em: 31 jul. 2020.

CFM. Conselho Federal de Medicina (Brasil). Resolução no 1.021/1980. Disponível em: https://sistemas.cfm.org. br/normas/visualizar/resolucoes/BR/1980/1021 Acesso em: 31 jul. 2020.

CFM. Conselho Federal de Medicina (Brasil). Código de Ética Médica: Resolução CFM 1931/2009. Disponível em: http://www.portalmedico.org.br/resolucoes/cfm/2009/1931_2009.htm. Acesso em: 10 ago. 2018.

CFM. Conselho Federal de Medicina (Brasil). Resolução CFM 2.232/2019. Disponível em: https://sistemas.cfm. org.br/normas/visualizar/resolucoes/BR/2019/2232 Acesso em: 31 jul. 2020.

CREMESP. Conselho Regional de Medicina do Estado de São Paulo. Fé vai a julgamento. Disponível em: http:// www.cremesp.org.br/?siteAcao=Saladelmprensa\&acao=crm_midia\&id=587. Acesso em: 1ㅇ ago. 2018.

FREDMAN, Sandra. New Horizons: incorporating socio-economic rights in a british Bill of Rights. Oxford Legal Studies Research Paper N.56/2010. Oxford, 2010.

MARINI, Bruno. O caso das Testemunhas de Jeová e a transfusão de sangue: uma análise jurídico-bioética. Revista Jus Navigandi, Teresina, ano 10, n. 661, 28 abr. 2005. Disponível em: https://jus.com.br/artigos/6641. Acesso em: 9 ago. 2018.

MENDES, Gilmar Ferreira; BRANCO, Paulo Gustavo Gonet. Curso de direito constitucional. 7. ed. rev. e atual. São Paulo: Saraiva, 2012.

MIRANDA NETO, Fernando Gama de; PEREIRA, Daniel Nunes. Legalidade, Legitimidade e crença jurídica: a celeuma entre o totalitarismo político de Schmitt e o entrincheiramento constitucional de Kelsen. In: CASTRO, Matheus Felipe de; AMAVA, Lídia Patricia Castillo (coord.). CONPEDI/UFSC. Anais [...]. Florianópolis: Conpedi, 2014. MORAES, Rodrigo; PIRES, Rodrigo. Transfusão de sangue em pacientes Testemunhas de Jeová: religião, ética e discurso ético-penal. Ciências Penais, v. 2, p. 216-228, jan./jun. 2005. RT on-line.

NERY JUNIOR, Nelson. Direito fundamental à liberdade religiosa. Soluções práticas de Direito, v. 1, p. 31-107, set. 2014. RT on-line.

NEVES, Rodrigo Santos. O direito à vida e à saúde diante da liberdade religiosa. Revista de Direito Constitucional e Internacional, v. 82, p. 145-158, jan./mar. 2013. RT On-line.

NOVAIS, Jorge Reis. Direitos sociais. Teoria jurídica dos Direitos sociais enquanto Direitos fundamentais. Coimbra: Coimbra Editora, 2010.

OMS. Organização Mundial de Saúde. Constituição (1946). Disponível em: http://www.direitoshumanos.usp.br/ index.php/OMS-Organiza\%C3\%A7\%C3\%A3o-Mundial-da-Sa\%C3\%BAde/constituicao-da-organizacao-mundial-da-saude-omswho.html Acesso em: 31 jul. 2020.

PEDRINI, Tainá Fernanda; SILVA, Pollyana Maria da. Aspectos jurídico-penais da transfusão de sangue em Testemunha de Jeová. In: RCJ - Revista Culturas Jurídicas, Niterói: UFF, v. 2, n. 4, 2015.

PORFIRIO, Fernanda. Pais acusados de proibir transfusão vão a Júri. In: CONJUR. Disponível em: https://www. conjur.com.br/2010-nov-18/tj-sp-manda-juri-pais-acusados-proibir-transfusao-sangue-filha. Acesso em: 10 ago. 2018. 


\section{Democracia}

RODRIGUES NETO, Eleutério. Saúde: promessas e limites da Constituição. Rio de Janeiro: Editora Fiocruz, 2003. SÃO PAULO. Tribunal de Justiça do Estado de São Paulo. Recurso em Sentido Estrito $n^{\circ}$ 993.99.085354-0. São Paulo, 2010.

SARLET, Ingo Wolfgang. A eficácia dos direitos fundamentais. 2. ed. Porto Alegre: Livraria do Advogado, 2001.

SARLET, Ingo Wolfgang. Algumas considerações em torno do conteúdo, eficácia e efetividade do Direito à Saúde na Constituição de 1988. In: Revista Eletrônica sobre a Reforma do Estado, n. 11, set./out./nov. 2007.

SARLET, Ingo Wolfgang; FIGUEIREDO, Mariana Filchtiner. Reserva do possível, mínimo existencial e direito à saúde: algumas aproximações. In: SARLET, Ingo Wolfgang; TIMM, Luciano Benetti (org.). Direitos fundamentais: orçamento e "reserva do possível". 2 ed., rev. e ampl. Porto Alegre: Livraria do Advogado, 2010. p. 13-50.

SARLET, Ingo Wolfgang; FIGUEIREDO, Mariana Filchtiner. Algumas considerações sobre o Direito Fundamental à Proteção e Promoção da Saúde aos 20 anos da Constituição Federal de 1988. In: Revista de Direito do Consumidor, n. 67, p. 125-172, jul./set. 2008.

TESTEMUNHAS DE JEOVÁ. Transfusões de sangue: uma longa história de controvérsias. Disponível em: https:// www.jw.org/pt/publicacoes/revistas/g20000108/Transfus\%C3\%B5es-de-sangue-uma-longa-hist\%C3\%B3ria-de-controv\%C3\%A9rsias/\#?insight[search_id]=cb377f2a-c010-4a43-9942-e61a6a89d\&insight[search_result_index]=8. Acesso em: 10 ago. 2018. 